\title{
The Italian contribution to the marketing literature
}

\author{
Marco Galvagno ${ }^{1}$ iD
}

Received: 9 February 2022 / Accepted: 10 February 2022 / Published online: 21 February 2022

(c) The Author(s) 2022

\begin{abstract}
The purpose of this study is to describe the contribution of Italian scholars to the international literature of marketing, and to identify the intellectual structure of Italian scholars' production, by mapping the co-authorships network and the main researched themes. Results highlight that Italian marketing scholars significantly intensified their productivity in the last ten years from different viewpoints. There has been a growing process of internationalization, a grownup of articles published by multiple co-authors in journals with higher impact factor, and a better performance in terms of citations of Italian papers compared to the international average. These results are all positive signals of a dynamic and developing community.
\end{abstract}

Keywords Italian marketing $\cdot$ Publishing $\cdot$ Science $\cdot$ Bibliometric indicators · Co-authorship network

\section{Introduction}

The development of the marketing field in Italy has been characterized by a slow and non-linear path. This process, which began in the 1960s, has seen a fast expansion since the 1990s. As reported by Varaldo et al. (2006), it is possible to identify four phases in the evolution of marketing science in Italy and specifically: the antecedent phase (1950s), the birth phase (1960s), the development phase (1970s-80s) and the consolidation phase (1990s). Therefore, it was only in the last decade of the twentieth century that Italian scholars began to take part in the international debate; indeed, the establishment of the Italian Society of Marketing (SIM), in 2004, gave an enormous cultural impetus, in terms of scientific contribution, methodologies, internationalization and collaboration among colleagues.

Since this is not the place to delve into the reasons for the initial Italian difficulties in the field of marketing scholarly research, we will only mention some of the factors that have characterized the evolving path of marketing studies in Italy, as

Marco Galvagno

marco.galvagno@unict.it

1 Department of Economics and Business, University of Catania, Catania, Italy 
reported by some previous studies (Bertoli \& Troilo, 2000; Ceccotti et al., 2017; Varaldo et al., 2006). In particular, factors related to the economic-industrial context and factors related to the academic context should be highlighted. Among the former, it is worth mentioning the particular configuration of the Italian economy, which is mainly characterized by small and medium-sized family businesses and specific forms of aggregation, such as industrial districts. Among the latter, there are, on one hand, the strong tradition of Economia Aziendale founded by Gino Zappa-which distinguished the Italian academy at the beginning - that conceived the firm as a "unitary economic complex" and was "reluctant to accept research related to specific functions" (Varaldo et al., 2006: p. 6); on the other hand, the difficulty of publishing in English and the prevailing form of academic dissemination of scientific knowledge which was essentially based on monographs.

At the end of the'90s, and even more in the first decade of the twenty-first century, some changes occurred, which pushed Italian scholars to produce research in English and publish it in international journals: the already mentioned birth of SIM and the definition of new criteria for research evaluation, following the establishment of the Italian National Agency for the Evaluation of Universities and Research Institutes (ANVUR) in 2006 (started operating in 2010), and the National Scientific Qualification (ASN) in 2012. Since then, the Italian scientific production in the field of marketing has experienced an exceptional development and has almost completely recovered the initial delay compared to other countries.

Based on the above premises, the purpose of this study is twofold: (1) to describe the contribution of Italian scholars to the international literature of marketing, and (2) to identify the intellectual structure of Italian scholars' production, by mapping the co-authorships network and the main researched themes.

The evolution of national scholar communities has been investigated in several business fields, such as accounting and finance in UK (Beattie \& Goodacre, 2004), accounting in Spain (Casanueva \& Larrinaga, 2013), or management in Italy (Marzi et al., 2017). However, there is a lack of this kind of studies with regard to national academic communities of marketing. Indeed, marketing studies have analysed the main topics of publications (Tellis et al., 1999), the productivity of single authors and institutions (Bakir et al., 2000; Cote et al., 1991), and the globalization of authorship (Stremersch \& Verhoef, 2005). To the best of our knowledge, no published studies have investigated the Italian scholars' contribution in marketing at the international level.

\section{Methodology}

The method used is the bibliometric one. It allows to analyse a specific field with the help of statistical techniques, by measuring the distribution patterns of publications, their impact in terms of citations and to visualize relationships among authors and topics. Specifically, we implemented two techniques, namely performance analysis and science mapping (Donthu et al., 2021). The former examines the performance of the Italian marketing scholars, by measuring the number of publications and citations, where publication is a proxy for productivity, while citation is a measure of 
impact and influence. The latter examines the relationships among Italian scholars and their production, by means of co-authorship analysis and keywords co-occurrence analysis.

In order to find all the relevant Italian publications within the marketing field, a specific search procedure was followed: using the advanced search feature of Elsevier's Scopus (accessed on August, 2021), we retrieved all articles published since 1960, within the business, management and accounting subject area, by scholars with an Italian affiliation. The 41,742 documents retrieved were then filtered by including only articles and reviews (excluding book chapters and editorials) written in English. The remaining 25,905 documents were filtered by including only those published in outlets listed as marketing journals in the Academic Journal Guide (AJG) 2021 of the Chartered Association of Business Schools (CABS). Using this search method, we identified 937 articles published in 68 journals in the period 1990-2021. For each of the 937 articles, we collected the following bibliographic data: authors' name and affiliation; journal's name; article's title, abstract and keywords, year of publication; citations received. The 937 articles have been written by 1,440 authors; 872 of them are Italian. All analyses were run on VOSviewer 1.6.17 and Gepghy 0.9.2.

\section{Results}

\subsection{Performance analysis}

Figure 1 shows the growth in number of publications from Italian scholars in marketing journals over time $(\mathrm{CAGR}=17.1 \%)$, resulting in a productivity per active year (PAY) of 31.2 articles. The first publication dated from 1990, but only a handful

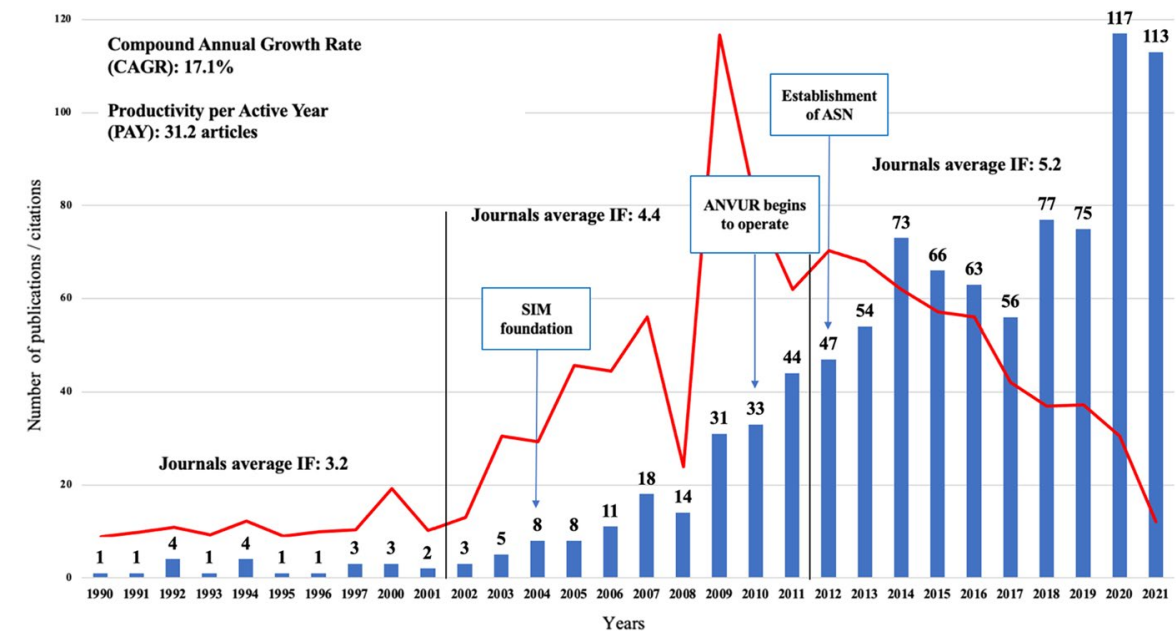

Fig. 1 Citations received and total number of articles published by Italian scholars on journals listed within the marketing field by the AJG 2021 of CABS (Scopus data) 
of papers were published between 1990 and 2003. The publication rate has gradually increased since 2009 , reaching a considerable rise in the last four years. Nearly the $80.0 \%$ of these publications appeared in the last ten years (2012-2021). In this regard, the PAY of the last two five-year periods (2012-2016 and 2017-2021) is 60.6 and 87.4 articles respectively. The 937 articles received a total of 23,105 citations (see the red line in Fig. 1), resulting in an average of citations per paper of 24.7 and an average of citations per year of 770 .

$60,0 \%$ of the 937 articles analysed has been written by three or more co-authors, and only $10,0 \%$ of them have a single author. Figure 2 shows the trend in the number of authors broken down by period. The evolution of the number of co-authors shows that the Italian marketing field has moved towards higher number of co-authorships from 2007 onward, in line with others fields of science and specifically with social science (e.g. Henriksen, 2018; Wuchty et al., 2007).

With regard to international collaborations, which have gradually increased over time, Table 1 shows that the performance of articles written by only Italian coauthors, in terms of average citation rate, is worse than the one of the articles written in collaboration with at least one foreign scholar.

The 937 articles analysed were published in 68 journals. Among them, those publishing the largest number of Italian academics' papers were: Industrial Marketing Management (IF =6.960; 3 stars on AJG); Journal of Retailing and Consumer Services (IF $=7.135 ; 2$ stars on AJG); Journal of Business \& Industrial Marketing (IF $=3.463 ; 2$ stars on AJG); International Journal of Retail \& Distribution Management $(\mathrm{IF}=3.771 ; 2$ stars on AJG); Psychology and Marketing $(\mathrm{IF}=2.939 ; 3$ stars on AJG); International Journal of Consumer Studies (IF=3.864; 2 stars on AJG); International Review of Retail, Distribution and Consumer Research (1 star on AJG); Journal of Global Fashion Marketing ( IF =0.49; 1 star on AJG); Journal of Fashion Marketing and Management (IF = 3.329; 1 star on AJG); Journal of Product \& Brand Management $(\mathrm{IF}=4.355 ; 1$ star on AJG); Journal of Brand Management

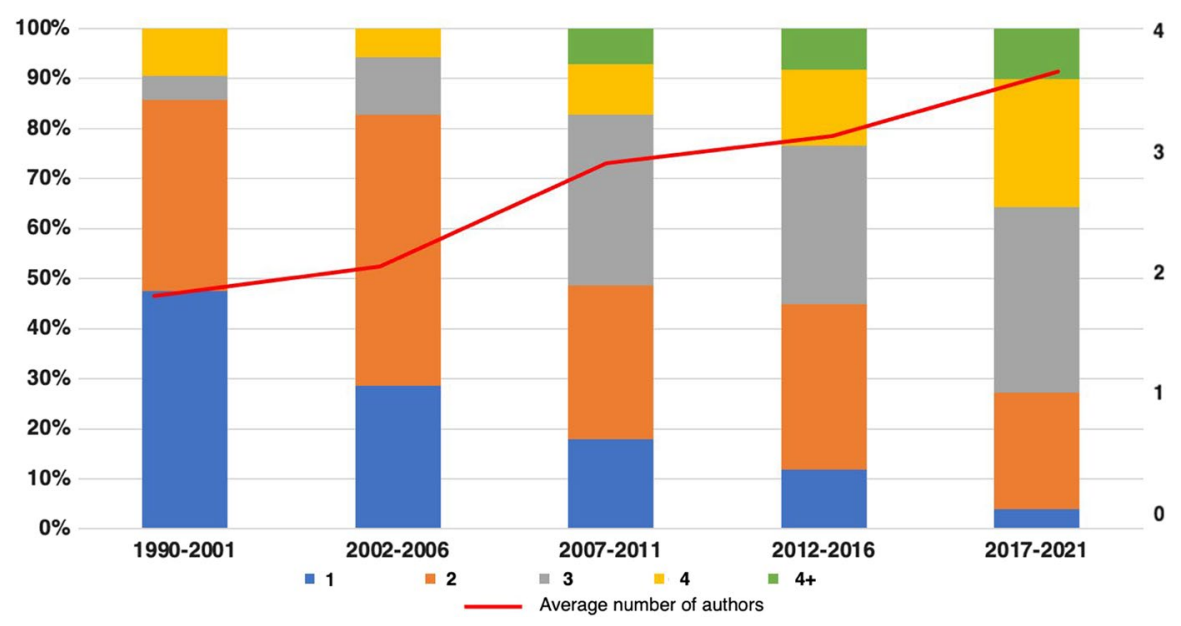

Fig. 2 Number and average of co-authors per article by period 
Table 1 Different performances in terms of average citation rate of publications with or without foreign co-authors

\begin{tabular}{llll}
\hline Indicator & Symbol & $\begin{array}{l}\text { Publications authored only } \\
\text { by Italian scholars (DOM) }\end{array}$ & $\begin{array}{l}\text { Publication authored at least } \\
\text { with one foreign scholar } \\
\text { (INT) }\end{array}$ \\
\hline $\begin{array}{l}\text { N. of publications by Italian } \\
\text { scholars }\end{array}$ & $T P$ & 420 & 419 \\
$\begin{array}{l}\text { Total N. of citations } \\
\text { Citations per publication* }\end{array}$ & $C$ & 6854 & 13,574 \\
$\begin{array}{l}\text { Percentage of publications not } \\
\text { cited }\end{array}$ & \%Pnc & $11.4 \%$ & 32.4 \\
& & & $12.6 \%$
\end{tabular}

*The $t$-test for the mean difference $(=16.1)$ yielded a statistically significant value of $t=-3.157$ $(p<0.05)$

(IF $=3.500 ; 2$ stars on AJG). These journals represent $16.0 \%$ of the sample and take in almost $50.0 \%$ of articles, with $41.0 \%$ of total citations received. Moreover, within the first twenty most represented journals, only five of them have 3 stars on AJG list, and none of them has 4 or more stars. Only $6.0 \%$ of all the 937 articles was published in a journal with 4 or more stars on the AJG list. Almost half of the articles has been published in journals focusing on specific topics as Industrial Marketing (15.8\%), Retail (15.7\%), and Consumer Behaviour (14.6\%); and 13.4\% of them has been published in journals focusing on General Marketing topics (13.4\%).

In order to analyse the research performance of the Italian scholars of marketing at the international level, we calculated the crown indicator (CPP/JCSm). This indicator compares the average number of citations of documents published by Italian scholars (CPP) to the average number of citations of all the documents of the same type (i.e. articles and reviews), published in the same journals and in the same period of time (JCSm). Table 2 shows how the indicator was calculated.

Table 2 Bibliometric indicators for the Italian marketing scholars

\begin{tabular}{|c|c|c|c|c|c|}
\hline Indicator & Symbol & 1990-2001 & $2002-2011$ & $2012-2021$ & 1990-2021 \\
\hline N. of publications by Italian scholars & $T P$ & 21 & 175 & 741 & 937 \\
\hline N. of journals & $J$ & 12 & 48 & 66 & 68 \\
\hline Total N. of citations ${ }^{a}$ & $C$ & 164 & 6177 & 9561 & 23,105 \\
\hline Citations per publication & $C P P$ & 7.8 & 35.3 & 12.9 & 24.7 \\
\hline Percentage of publications not cited & $\%$ Pnc & $4.8 \%$ & $1.7 \%$ & $14.3 \%$ & $11.7 \%$ \\
\hline Mean citation rate of journal group $(\mathrm{J})$ & $J C S m$ & 5.4 & 24.4 & 13.2 & 21.3 \\
\hline $\begin{array}{l}\text { Citations per publication, compared to } \\
\text { citation rate of journal group }\end{array}$ & $C P P / J C S m$ & 1.4 & 1.5 & 0.9 & 1.2 \\
\hline
\end{tabular}

${ }^{a}$ For articles published in a certain period of time $t_{0}-t_{n}$, citations are counted during the period of five years after, from $t_{0}$ to $t_{n+5}$ for both the groups (Italian articles and all international articles). For articles published between 1990 and 2001, citations are counted during the period of 1990-2006; for articles published between 2002 and 2011, citations are counted during the period of 2002-2016; for articles published between 2012 and 2021, citations are counted during the period of 2012-2021. 
As shown in the last row of Table 2, the CPP/JCSm indicator varies from 0.9 to 1.5 , where a value of 1.2 signals that the impact of the Italian research community exceeds the international average: i.e. Italian marketing publications are cited $20 \%$ more than the world average, although there was a sharp decline after 2012.

\subsection{Science mapping}

In order to represent the intellectual structure of the Italian marketing community, we developed a co-authorship analysis to describe the network of collaborations among scholars, and a keywords co-occurrence analysis on the articles to discover the main researched topics.

Figure 3 represents the three sub-networks in three sub-periods. Each node represents an author, while a tie represents a co-authorship between two authors in the same article. It is useful to highlight some interesting aspects. In the first period, 1990-2001, the sub-networks are mainly composed of isolated researchers or couple of co-authors; the network has a diameter of 2 and an average degree of 0.08 . This highlights the work of individual authors working in different universities, who collaborate with other researchers working at the same university. The second period, 2002-2011, highlights that collaboration increases, and although there are many more individual researchers at the edge of the network, stable groups of coauthors from different universities begin to form at the centre. It is also worth noting that some sub-networks of scholars are linked together by the so-called bridges: i.e. researchers who act as a link between different sub-networks. The diameter of the network, in this period, is 5 and the average degree is 1.5 . The last period, 2012-2021, points out a process of articulated growth of the Italian community, with almost all the scholars linked with someone else, and the presence of a big macro-network in the centre, underlining collaborations among different groups (represented in different colours). However, it is still possible to see the presence of some isolated groups with a strong internal collaboration activity, but disconnected from the centre. The network's diameter is 15 and the average degree is doubled, compared to the previous period, with a value of 3.2 .

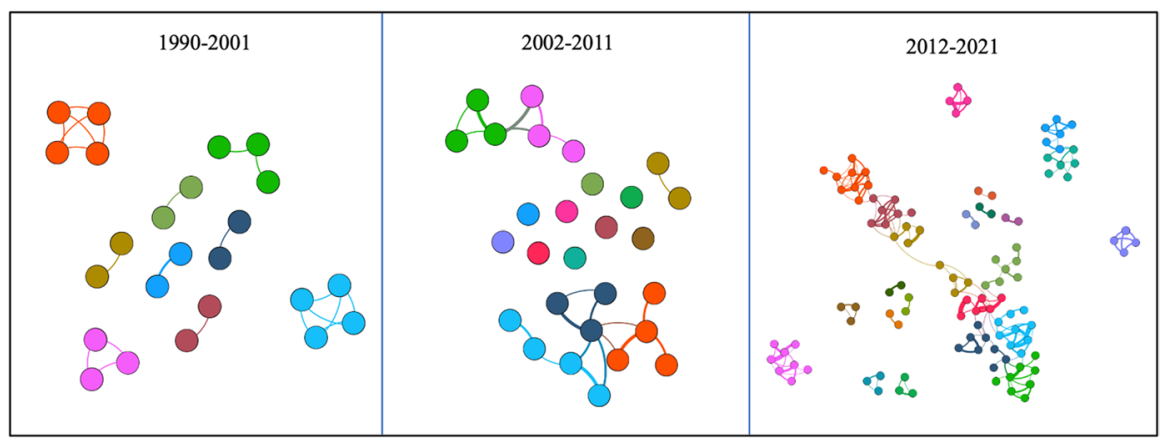

Fig. 3 The co-authorship networks in the three sub-periods 
The results of the keywords co-occurrence analysis are shown in Fig. 4. It reports the main topics addressed by Italian scholars in the three different time-periods. Between 1990 and 2001 there are not specific topics. Articles, in this time window, address general themes mainly related to the internationalization of retailing, marketing strategy and segmentation, trends in consumer behaviour in Italy and quality in services. Between 2002 and 2011 topics start to get more specific. Particularly, the marketing cluster turns into a more composite set of topics: the role of brand, communication, and the Internet; the retail cluster is then diversified between B2B relationships, supply chain management, often applied to the fashion industry; studies on services address co-creation processes, while consumer behaviour studies begin to deal with the classical concepts of satisfaction and loyalty. Within the last time window, 2012-2021, the Italian contribution is enriched by more specialized and empirical studies, characterized by a focus on Country of Origin (COO) and luxury, technological innovation in retail, B2B networks and small business (SME), sustainability and Corporate Social Responsibility (CSR), buying process, consumer experience and emotions.

\section{Conclusions}

This work aimed to identify the contribution of the Italian scholars to the marketing literature. The first objective was to quantify the scientific productivity and the performance of Italian marketing academics. The second objective was to discover the evolution of collaborations among authors and map the main topics of their publications.

Results highlight that Italian marketing scholars significantly intensified their productivity in the last ten years from different viewpoints. There has been a

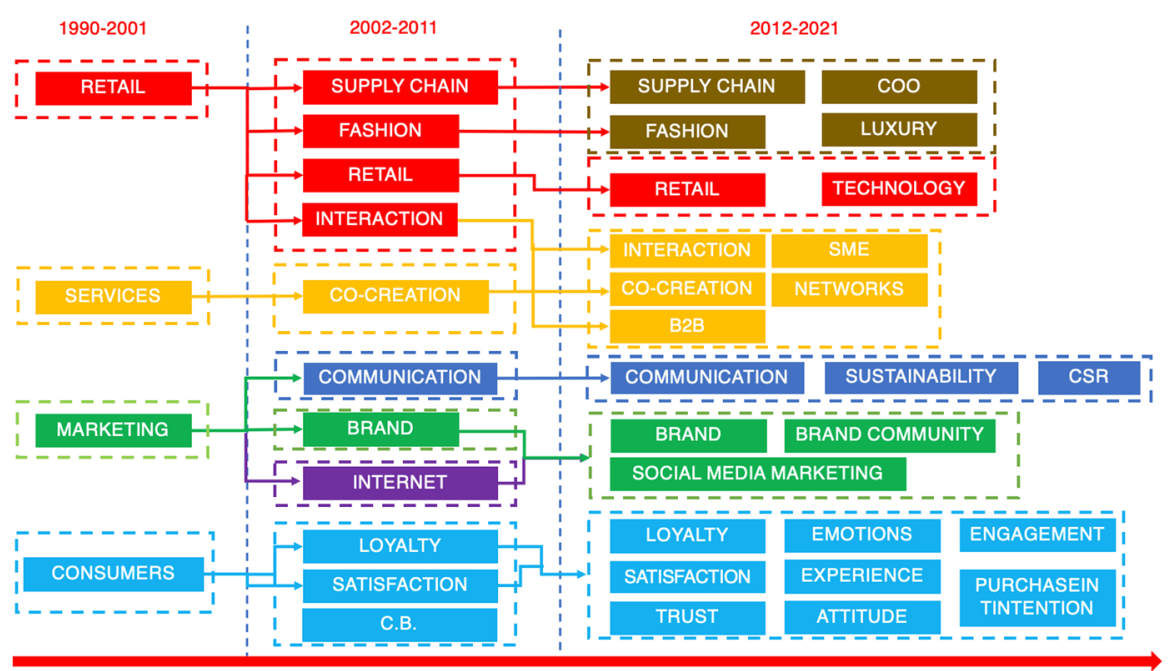

Fig. 4 The evolution of topics addressed 
growing process of internationalization, a grownup of articles published by multiple co-authors in journals with higher impact factor, and a better performance in terms of citations of Italian papers compared to the international average. These results are all positive signals of a dynamic and developing community.

At the moment, the Italian marketing research network is characterised by a big giant connected component with relatively well-connected researchers and many other small components, characterised by authors publishing either alone or with few co-authors. Indeed, this study focuses on marketing journals listed on the AJG of CABS, but Italian marketing scholars regularly publish many articles, book chapters and international monographs that are not considered in this analysis. This certainly reduces the comprehensiveness of the results. Further research, by means of other data sources, could help to complete the analysis. Furthermore, this study is mainly descriptive and does not offer insights for the underlying mechanisms that account for these observed patterns. Further research efforts, directly involving Italian marketing scholars as informants will be performed in order to address this issue.

Open Access This article is licensed under a Creative Commons Attribution 4.0 International License, which permits use, sharing, adaptation, distribution and reproduction in any medium or format, as long as you give appropriate credit to the original author(s) and the source, provide a link to the Creative Commons licence, and indicate if changes were made. The images or other third party material in this article are included in the article's Creative Commons licence, unless indicated otherwise in a credit line to the material. If material is not included in the article's Creative Commons licence and your intended use is not permitted by statutory regulation or exceeds the permitted use, you will need to obtain permission directly from the copyright holder. To view a copy of this licence, visit http://creativecommons.org/licen ses/by/4.0/.

\section{References}

Bakir, A., Vitell, S. J., \& Rose, G. M. (2000). Publications in major marketing journals: An analysis of scholars and marketing departments. Journal of Marketing Education, 22(2), 99-107.

Beattie, V., \& Goodacre, A. (2004). Publishing patterns within the UK accounting and finance academic community. The British Accounting Review, 36(1), 7-44.

Bertoli, G., \& Troilo, G. (2000). L'evoluzione degli studi di marketing in Italia (p. 10). Dalle origini agli anni Settanta. Università degli Studi di Brescia.

Casanueva, C., \& Larrinaga, C. (2013). The (uncertain) invisible college of Spanish accounting scholars. Critical Perspectives on Accounting, 24(1), 19-31.

Ceccotti, F., Mattiacci, A., \& Nosi, C. (2017). Trends in marketing studies: A longitudinal analysis of leading Italian academic journals (2005-2015). Mercati e Competitività, 4, 77-102.

Chartered Association of Business Schools. (2021). Academic Journal Guide 2021. https://charteredabs. org/academic-journal-guide-2021-view/. Accessed on August 2021.

Cote, J. A., Leong, S. M., \& Cote, J. (1991). Assessing the influence of journal of consumer research: A citation analysis. Journal of Consumer Research, 18(4), 402-410.

Donthu, N., Kumar, S., Mukherjee, D., Pandey, N., \& Lim, W. M. (2021). How to conduct a bibliometric analysis: An overview and guidelines. Journal of Business Research, 133, 285-296.

Henriksen, D. (2018). What factors are associated with increasing co-authorship in the social sciences? A case study of Danish Economics and Political Science. Scientometrics, 114(3), 1395-1421.

Marzi, G., Caputo, A., \& Dabić, M. (2017). Management lessons from Italy: A bibliometric analysis of top Italian based scholars and studies published from 1985 to 2015. International Journal of Critical Accounting, 9(4), 269-288. 
Stremersch, S., \& Verhoef, P. C. (2005). Globalization of authorship in the marketing discipline: Does it help or hinder the field? Marketing Science, 24(4), 585-594.

Tellis, G. J., Chandy, R. K., \& Ackerman, D. S. (1999). In search of diversity: The record of major marketing journals. Journal of Marketing Research, 36, 120-131.

Varaldo, R., Dalli, D., Resciniti, R. (2006). Marketing-non-marketing all'italiana: virtù, limiti e prospettive. In V Congresso Internazionale Marketing Trends.

Wuchty, S., Jones, B. F., \& Uzzi, B. (2007). The increasing dominance of teams in production of knowledge. Science, 316(5827), 1036-1039.

Publisher's Note Springer Nature remains neutral with regard to jurisdictional claims in published maps and institutional affiliations. 